\title{
Inhibitors and Their Intra-Relationships Influencing the Adoption of Stabilised Earth Construction to Alleviate the Urban Housing Crisis in Zimbabwe
}

\author{
Mohammad Sharif Zami \\ Department of Architecture, College of Environmental Design, King Fahd University of Petroleum \& Minerals \\ (KFUPM), Dhahran, KSA \\ Email: mdszami@kfupm.edu.sa
}

Received 4 June 2014; revised 12 July 2014; accepted 14 August 2014

Copyright (C) 2014 by author and OALib.

This work is licensed under the Creative Commons Attribution International License (CC BY). http://creativecommons.org/licenses/by/4.0/

(c) (i) Open Access

\section{Abstract}

Stabilised earth is an alternative building material which is comparatively cheaper than conventional building material in Zimbabwe. However, there are inhibitors which make it unpopular amongst the Zimbabwean construction professionals and general population, though it has a high potential to alleviate the urban housing crisis. This paper aims to identify and highlight these inhibitors and refines them through a series of in-depth interviews. First, a critical literature review method is adopted in this paper to identify the inhibitors influencing the adoption of this building material to address the urban housing crisis and second, the identified inhibitors are refined through the in-depth interview method to determine those influencing the widespread adoption of stabilised earth as a construction material to address urban housing crisis in Zimbabwe.

\section{Keywords}

Construction, Stabilised Earth, Inhibitors, Professionals, Urban Housing, In-Depth Interview

Subject Areas: Development Economics, Environmental Economics

\section{Introduction}

Over the 2000-2010 decade, the Southern Africa sub-region retained its position as the most urbanized one on the continent, with the rate increasing from 53.8 to 58.7 percents [1]. Unfortunately, the cities of developing countries are not planned for these magnitudes of growth in population influx, nor do they in reality have the required jobs and facilities to support such expansion [2]. Urban facilities, especially housing, have failed to 
meet the growing demand of the rural poor [3]. The housing shortage alone in African cities ranges from 33\% to $90 \%$ [4]. This has led to many people resorting to renting backyard shacks and squatting on illegal land. There are no provisions for social services and utilities in squatter settlements. However, it is evident from the literature review that experimental stabilised earth construction projects are a success in many developing countries, such as India, Sudan, Zimbabwe, and South Africa and in developed countries, such as Australia, Germany, and France in addressing the urban housing crisis [5]-[7]. Thus the question arises, why is stabilised earth construction not yet widely adopted to address the urban housing crisis? To investigate the reason, it is logical to review the literature and find out whether there has been any structured research carried out to identify the inhibitors influencing the widespread adoption of contemporary earth construction. Therefore, it is pertinent to analyse the inhibitors influencing the adoption of this technology. A critical literature review method is adopted in this paper to investigate and identify the inhibitors which are then validated with the help of a series of in-depth interviews. The following section reviews the literature on inhibitors influencing the adoption of stabilised earth construction to address the urban low cost housing crisis.

\section{State of the Art Review on Inhibitors Influencing the Adoption of Earth Construction}

It is evident that experimental stabilised earth construction projects in low cost urban housing are a success in many developing countries in Africa [6] [7]. Lack of standardised earth-based materials, rapid urbanisation, changing lifestyles and increased adoption of energy-intensive modern construction materials have led to a steep decline in the adoption of traditional/vernacular earthen structures [8].

Various earth-building awareness initiatives and performance-enhancement studies were undertaken in a number of African countries [9]. In Nigeria, tests to improve the durability and affordability of earth building, which has been promoted as an alternative for low-cost housing for the poor, were carried out [10]. It has also been reported that compressed stabilised earth blocks were 'successfully' used in low income housing in Sudan [5]; users' perceptions were however not recorded. Similarly, the potential of earth building in Botswana has also been studied, with the aim of developing a suitable material mix for a compressed earth block technique and recommendations were put forward on the proportions of the block mix, mixing methods, stabilisation, strengthening and transport. The study concluded that further work was required to establish the wider use of earth blocks and it encouraged earth block use for housing in Botswana, Namibia, and Zimbabwe, given the similarity in their soils [11]. Under pressure for modernisation, the Zambian government has so far neglected the promotion of vernacular construction methods and materials [12]. Furthermore, the Zambian Institute of Scientific Research and the Copperbelt University carried out research on traditional construction technologies, but the dissemination of their findings has not been implemented effectively [13]. A study identified several barriers to earth building in Uganda, including the need for new legislation, technical training programmes, public awareness of sustainability, and knowledge-sharing [14]. Table 1 lists the inhibitors from the intensive literature review.

All the inhibitors of contemporary earth construction identified in Table 1 lack empirical evidence and it would seem from a thorough review of the literature that sparse research to date has been undertaken to substantiate whether the inhibitors in Table 1 are real or mere speculation. It is questionable whether they are the author's perception, and thus lack empirical data to substantiate the findings. Therefore, this paper aims to refine the inhibitors influencing the adoption of stabilised earth construction by professionals to address the urban low cost housing crisis in Zimbabwe. It is essential to note that inhibitors identified in Table 1 and drawbacks of earth construction are the same. According to the literature review drawbacks are considered as inhibitors, too.

\section{Research Methodology}

After a critical review of the existing literature, it appears that there is a lack of structured research carried out to date to identify and understand the inhibitors influencing the adoption of stabilised earth construction in urban low cost housing. In addition, the inhibitors identified by different practitioners and researchers mentioned in the literature lack empirical data and validation through the execution of a methodological research process. The inhibitors found in the literature are written in the light of the researcher's experience and perceptions working with this building material. Therefore, the research technique adopted in this paper is in-depth interviews which effectively collects data from construction professionals and compares the list of inhibitors found in the existing 
Table 1. Inhibitors influencing the adoption of contemporary earth construction [37].

\begin{tabular}{|c|c|}
\hline $\begin{array}{l}\text { Inhibitors influencing adoption of stabilised earth construction } \\
\text { (Summarised from the literature review) }\end{array}$ & Authors \\
\hline 1) People’s mistaken perceptions and cultural problems. & [5] [9] [15]-[25] \\
\hline $\begin{array}{l}\text { 2) Lack of knowledge, skills, and understanding amongst professionals, } \\
\text { government, donors, and users. }\end{array}$ & [9] [15] [20]-[22] [26] [27] \\
\hline 3) It requires extra money, labour and time. & [15] [18] [19] [28] [29] \\
\hline 4) Lack of technologies and resources. & {$[20][22][29]$} \\
\hline 5) Lack of courses and training programmes in universities. & [20] [26] [30] [31] \\
\hline 6) Lack of care and focus on the environment, aesthetics, and comfort. & [20] [26] [32] [33] \\
\hline 7) Lack of building codes and policies to adopt earth construction. & [5] [15] [21] [34] [35] \\
\hline $\begin{array}{l}\text { 8) Professionals make less money from their customary percentage on } \\
\text { total cost of earth construction projects. }\end{array}$ & [36] \\
\hline 9) Housing credit and insurance are difficult to obtain from financial institutions. & {$[16]$} \\
\hline 10) Low technical performance of earth as a construction material. & [5] [21] [22] [29] \\
\hline
\end{tabular}

literature.

Kelly [38] states, "Whatever the world may be, man can come to grips with it only by placing his own interpretations upon what he sees. While his ingenuity in devising suitable constructions may be limited, and many misfortunes therefore come to pass, still it is he, not facts, who holds the key to the ultimate future". Supporting Kelly's statement Pidd [39] states that, "this means that as we enlarge our experiences in daily life, we try to make sense of them. We do this by using our imagination in anticipating what the consequences might be of what we have experienced". In order to understand the inhibitors, the in-depth interview method unlocked the vital experiences of the experts represented by the practitioners, academics and researchers. "the aim of a researcher should be to ensure that the methods used enable maximum convergence (transfer of meaning) between themselves and the respondent". Feedback is thus paramount to achieving this convergence for he further explained, "in a research context, feedback is knowledge of results travelling back to the researcher from the respondent, and can take many forms such as verbal and written reactions, facial expressions and body movements" [40]. Interviews, in Loosemore's [40] opinion, are able to "facilitate feedback through two-way communication". Interviews represent a powerful tool in the building of a theory, not only by eliciting perceptions of the concept from the experts, that is the industrial practitioners, but also, the theory-building process is supplemented by the contextualised data gathered from the reports of the practitioners' experiences [41].

The research of this paper executed in-depth interviews with experts who are experienced in the Zimbabwean construction industry. The refinement process of the inhibitors through a series of in-depth interviews played an appropriate and effective role to highlight any sensitive factors and hidden agendas in the Zimbabwean context. The acquisition of this set of data enabled the researcher to construct a more effective base of knowledge and to refine the generic set of inhibitors.

\subsection{Data Collection, Analysis and Presentation Technique of In-Depth Interview}

Analysing in-depth interviews involves reviewing the records of the interviews and taking notes to keep track of the findings that are emerging and the two most common strategies for organising notes are [42].

- Organising by question: In this strategy, notes are recorded as “answers to questions”, that is the respondent's remarks related to the questions are recorded under each question. It is important to note that interviews follow the flow of a conversation more than they follow a script, and so questions may be answered or returned to at different points in the interview. With this strategy, any additional remarks relating to this question would be recorded in the same place, even if the question is brought up later on in the interview.

- Organising by theme: In this strategy, comments that relate to specific themes (pre-determined and those that emerge in the course of an interview) are grouped together, regardless of the question they relate to. For example, under the theme "disadvantages", comments might be included about inhibitors in response to questions about the barriers that prevent the adoption of stabilised earth construction technology. 
Both strategies may be used concurrently. For example, content analysis can be begun by organising by question, but switch to a thematic strategy as themes emerge over the course of the interviews [42]. The researcher of this study used both strategies concurrently to analyse the data.

In-depth interviews are flexible in that they can be presented in many ways; there is no specific format to follow [43]. However, like all evaluation results, justification and methodology of the study should be provided, as well as any supporting information (that is copies of instruments and guides used in the study). In-depth interview data may stand alone or be included in a larger evaluation report. Care should be taken in presenting the in-depth interview data, such as, using qualitative descriptors rather than trying to "quantify" the information [43]. One might consider using qualifiers such as "the prevalent feeling was that ..." or "several participants strongly felt that ...” or even "most participants agreed that ...” Numbers and percentages sometimes convey the impression that results can be projected on to a population and this is not within the capabilities of this qualitative research procedure [43]. Providing quotes from respondents throughout the report adds credibility to the information. The researcher should be careful that the respondent is not identified and not to provide quotes that are easily traced back to an individual, especially if confidentiality is promised [43]. In-depth interview data can be displayed in tables, boxes and figures to make it easier to read.

The aim of the in-depth interview is to refine and validate the generic inhibitors derived from the literature review considering a Zimbabwean context. The inhibitors refined by conducting the in-depth interviews are based on the opinions of the Zimbabwean experts and lead to an understanding of the inhibitors influencing the widespread adoption of stabilised earth construction in Zimbabwe. The following section discusses the selection process and profiles of the Zimbabwean experts that participated in the in-depth interviews.

\subsection{Selection of the Interviewees}

This section explains the selection process of the interviewees and the process of the interview. It is worth mentioning here that there are very few Zimbabwean earth construction experts who have worked or are at present working in Zimbabwe. Therefore, in essence, data was collected through face to face interviews with four experts and telephone conversations with four more experts. The political and economic problems of Zimbabwe drove away most of the experienced and qualified Zimbabwean construction professionals to the neighbouring countries like South Africa and Botswana and other developed countries like the United Kingdom and America. Therefore, conducting the interviews in Zimbabwe was not possible as the majority of experienced construction professionals had migrated. It is notable that the major challenges faced in the identification of Zimbabwean construction professionals appropriate for these in-depth interviews were as follows:

- Very few Zimbabwean construction professionals are aware of and skilled in contemporary earth construction. The few Zimbabwean professionals skilled in this technology are expatriate Zimbabweans.

- The few young practising professionals who are aware of this technology are at present out of their country due to the political and economical problems the country has been facing.

- The few NGOs involved in promoting earth construction in Zimbabwe have either closed down or are not promoting this technology due to shortage of manpower and resources.

A total of fourteen (14) experts were contacted through email. Telephone calls were made to follow up the invitation of the experts to take part in the interview. Eight (08) experts agreed to take part in the interview pertaining to this study. Three (03) of the experts were academician researchers with an average of over thirty years work experience. The remaining five (05) experts were practitioners with an average of eight years practical experience (see Table 2).

In choosing experts for this in-depth interview, a set of criteria was considered, and accordingly a list of eight (08) experts were identified from the private and public sector deemed to have the required knowledge and experience of the subject. The set of criteria was as follows:

- Zimbabwe born and locally trained construction professionals who are knowledgeable in contemporary earth construction as they would be suitable to explain the local factors influencing the adoption of stabilised earth construction in Zimbabwe.

- The Standard Association of Zimbabwe published a Standard Code of Practice on the use of rammed earth technology in 2001. People who were involved in the formulation of this code of practice were considered as potential interviewees.

- Construction professionals who were not born and trained in Zimbabwe, but had worked in Zimbabwe, and 
Table 2. Expert's participation in in-depth interview.

\begin{tabular}{cc}
\hline Profession/background of interviewees & Number of interviewees \\
\hline Academician researcher & 02 \\
Practitioner & 05 \\
Practitioner researcher & 01 \\
Total & 08 \\
\hline
\end{tabular}

are knowledgeable in contemporary earth construction as they were competent in explaining local factors in the light of their international experience.

Brief profiles of the eight (08) experts who participated in in-depth interviews are shown in Table 3.

\section{Analysis and Discussion of Findings from the In-Depth Interviews}

All the interviewees were asked 10 open ended questions about the 10 inhibitors identified from the literature review (Table 1). At the end of each interview, all interviewees were also asked an additional question as to whether there is any other inhibitor that was not mentioned during the interview.

All eight (08) interviewees recognised that stabilised earth construction is associated with poverty and agreed that the social stigma surrounding earth construction is an inhibitor to adopting this technology in Zimbabwe. Similarly, all interviewees agreed that Zimbabweans are reticent to change and prefer to build in a way that they are familiar with. Interviewee "Q" stated, "Construction globally is a very conservative pursuit, and it is conservative for a number of reasons. Think about the architecture profession for instance. You train for five or six years and your entire training is carried out on the basis of the European and American modern movement, that is to say using concrete and steel. When you go into practice, you put your training into practice following the building regulations. Somebody comes along and says, "Hey let's do something completely different." You don't know what it is, so you reject it and you fight against it because it doesn't fit in with your work skill set. That same conversation is true for civil engineers, planners, surveyors and funders." The statement expressed concern that not only are Zimbabweans reticent but professionals also are universally reticent and they prefer to practice according to their training from the university.

A mixed response was recorded from the interviewees when they were asked if stabilised earth construction required extra labour and cost in Zimbabwe. Seven of the interviewees agreed that it did not because they argued that although the method of this construction in Zimbabwe, as in many other developing countries, can be highly labour intensive, the unemployment rate is very high and therefore the country has an immediately accessible large pool of cheap labour, whereas in the UK the labour cost is very expensive. Cost in the UK is governed by the cost of labour; in Zimbabwe it is governed by the cost of materials, particularly the cost of cement in relation to stabilised earth. The economic benefits will depend on how much cement is used and the technology used in construction. For Compressed Stabilised Earth Block (CSEB), presses are required; rammed earth requires formwork. In summary, these technologies can be cheaper in Zimbabwe, given the cheap labour cost. In addition, interviewee "Q" commented that un-stabilised earth construction does not require additional labour and cost.

According to six interviewees, information on stabilised earth construction products and techniques is inadequate for both professionals and users compared to conventional brick and block construction in Zimbabwe. Similarly seven interviewees agreed that stabilised earth construction is less accepted by the majority of Zimbabwean professionals, and that there is less profit to be made by working on earth construction projects. In regards to professional fees, interviewee "V" stated that, "Architect's fees are charged on the total cost of the building. Therefore, if the cost of the earth building is lower than the cost of the conventional brick and block building, architects will get less money. That's why professionals tend to increase the cost of the building by suggesting costly materials to the clients."

Zimbabwe city council authorities included stabilised rammed earth, soil blocks and brick construction standards in their Model Building By-Laws [44] in 2004. Zimbabwe was the only country in Southern Africa which adopted such stabilised earth construction standards in their building by-laws. However, Zimbabwe does not have a policy to minimise the use of energy intensive materials like burnt clay bricks, concrete, and steel for housing projects and there is no legislation to protect earthen buildings. 
Table 3. Brief profile of the experts who participated in the in-depth interview.

\begin{tabular}{|c|c|c|c|c|}
\hline$\dot{z}$ & 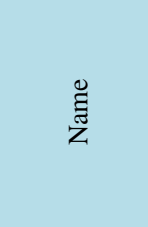 & 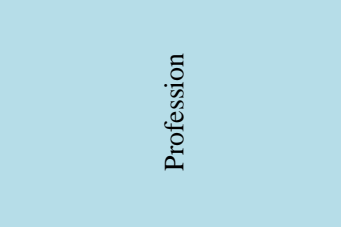 & 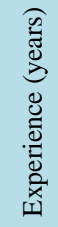 & 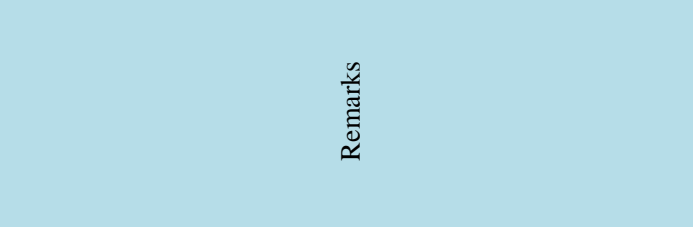 \\
\hline 01 & Expert “O” & $\begin{array}{c}\text { Practising Architect in } \\
\text { conservation, Professor in } \\
\text { Architecture. }\end{array}$ & 40 & $\begin{array}{l}\text { Worked in many African countries including Zimbabwe. } \\
\text { Published many journal papers on vernacular architecture. }\end{array}$ \\
\hline 02 & Expert “P” & $\begin{array}{l}\text { Professor in Civil } \\
\text { Engineering. }\end{array}$ & 25 & $\begin{array}{l}\text { Author of a rammed earth construction book and many } \\
\text { journal papers. Worked for several years in Zimbabwe. }\end{array}$ \\
\hline 03 & Expert “Q” & $\begin{array}{l}\text { Director of an earth } \\
\text { construction practice. }\end{array}$ & 24 & $\begin{array}{l}\text { Author of Zimbabwe code for rammed earth structure. } \\
\text { Builder of many earth structures in Zimbabwe and UK. }\end{array}$ \\
\hline 04 & Expert "R" & Practicing Architect & 8 & One of the Zimbabwean architects also trained in Zimbabwe. \\
\hline 05 & Expert "S" & Urban Designer, Architect & 8 & One of the Zimbabwean architects also trained in Zimbabwe. \\
\hline 06 & Expert “T” & Design and Project Architect & 8 & One of the Zimbabwean architects and trained in Zimbabwe. \\
\hline 07 & Expert "U” & Professional Architect & 8 & One of the Zimbabwean architects and trained in Zimbabwe. \\
\hline 08 & Expert "V” & $\begin{array}{c}\text { Architect/Landscape } \\
\text { Architect, } \\
\text { Professor in Architecture. }\end{array}$ & 42 & $\begin{array}{l}\text { Designer of earth building for University of Malawi. } \\
\text { Worked many years in Southern Africa. Worked as an } \\
\text { external examiner of undergraduate and postgraduate } \\
\text { architecture degree programmes in Zimbabwe. }\end{array}$ \\
\hline
\end{tabular}

According to all the academician researcher interviewees, skilled labour and suitable machines for stabilised earth construction are available in Zimbabwe, whereas all the practitioner interviewees refuted this claim. Interviewee "V" stated that, "There is no skilled labour and suitable machinery. With the current economic situation, most manufacturing companies have closed down and most experienced and trained people have moved out of the country, leaving a few exceptional people with skill that may be used in the setting up of a plant to manufacture CSEB and to run it." All interviewees agreed that getting insurance and loans from the banks and other financial organisations is difficult in Zimbabwe if the building is made out of earth. With regards to availability of insurance and loans for earth building in Zimbabwe, interviewee "U" stated that, "Obtaining credit and insurance on a property built in SEC (Stabilised Earth Construction) may be difficult because the other professionals are not conscious of the advantages and disadvantages of the use of SEC in urban areas."

According to the majority of experts, there is no lack of good quality exemplar earthen architecture in Zimbabwe as expert "O" stated, "There were a number of good quality exemplar earthen structures designed by Mick Pearce in Zimbabwe. Besides, ITDG (Intermediate Technology Development Group), CSIR (Council for Scientific and Industrial Research) and SADC (Southern African Development Community) also constructed several stabilised earthen good quality structures in Zimbabwe which were the structures themselves appreciated by the people. I do not know any substandard earthen structure in Zimbabwe. I think good quality exemplar earthen architecture, especially in low income houses, exists in Zimbabwe. Therefore, this is not an inhibitor in the Zimbabwean context." In addition, all the experts agreed that there was no substandard earth structure in urban Zimbabwe that they were aware of and therefore, this is not an inhibitor influencing the adoption of stabilised earth construction in Zimbabwe. According to experts, the only substandard earth structure can be found in the rural areas.

All interviewees agreed that the promotion of stabilised earth construction by foreign agencies in Zimbabwe is not an inhibitor, as expert "P" stated, "Well, in some countries, especially in developing countries, people might react and express reluctance to accept anything promoted by the NGO's or foreign agencies. But I do not know anything like this in Zimbabwe.” Moreover experts also stated that Zimbabweans appreciate any developed technologies, no matter whether it is by their government or foreign agencies, as expert " $U$ " stated, "Zimbabweans appreciate if any developed technology is introduced by the foreign agencies. Earth construction is cheap, therefore, people appreciate it." Similarly expert “Q” stated, "In Zimbabwe, people accepted earthen structure because it is cheap, not that they thought it is poor. Maybe people have mistaken perceptions about the material 
earth but the projects I was involved in, people always expressed their positive responses to earth buildings in Zimbabwe." The statement showed that Zimbabweans are progressive, well accommodative and it is in their nature to accept and adopt advanced technologies for their benefit.

When experts were asked, whether the understanding of the process of contemporary stabilised earth construction is adequate or not amongst Zimbabwean professionals, the majority of experts agreed that it is not adequate. Expert “O” stated that, "No, it is not, simply because they haven't had the experience using it, or experience through using it. The opportunity of doing it isn't there. There is very little opportunity, very few people who have been able to see it the work being done in CSIR (Council for Scientific and Industrial Research) and only one or two other architects like Mick Pears have designed in this way in the rural areas. Most people do not have opportunities." The statement also highlighted the reason for not having adequate understanding because of fewer chances to understand the process by being involved in it onsite. Therefore, inadequate understanding of stabilised earth construction is an inhibitor in Zimbabwe. However, expert "P" expressed his opinion otherwise, as he stating, "The answer is 'Yes' and 'No'. If you take the question as, is understanding quate? ..... then the answer is 'yes', because it is adequate for the current market, because there is no demand for it. As there is no demand for it then you can say the knowledge base is adequate for the demand. The market will not increase as long as the demand does not increase. I have to say the market awareness and understanding technical knowledge are not adequate. But it is adequate for the current market, because there is no market for it." The statement confirmed that there is intra-relationship between the adoption inhibitors and drawbacks of stabilised earth construction and Figure 1 illustrates this intra-relationship.

There is no lack of awareness of environmental sustainability amongst the Zimbabwean professionals, according to the interviewees. Interviewee "P" stated that, "In 2009 there was no lack of awareness of global warming and climate change amongst the professionals. I would be surprised if any practising architect or engineer is not at least aware of and has the familiarity with principle of the background of climate change and the contribution that building and infrastructure would make to climate change.” The majority of experts also expressed that the professionals in Zimbabwe are not dedicated to the issues of environmental sustainability. In addition, all the interviewees agreed that the availability of training programmes in stabilised earth construction is not adequate in Zimbabwe to train the professionals, as "Q" stated, "There are no base line skills to do so. There is apparently not the driving economic imperative within the professional class."

Similarly expert "P" states, "There are no such training programmes in UK/ZW because there is no market for the training programmes. People are not being asked to be trained. So it is a vicious circle. If market conditions changed and everybody decided, especially if the government had a programme of promoting the building with earth and $10 \%$ of the market is going to be stabilised earth, then it could be said that we cannot deliver $10 \%$ of buildings in stabilised earth because the knowledge is not there. Therefore, if the market develops, the training will develop, and knowledge will develop.” The statement explained that there is an intra-relationship between the adoption inhibitors and drawbacks of stabilised earth construction and Figure 2 illustrates this intra-relationship. In addition, universities and polytechnics do not teach contemporary earth construction technology in Zimbabwe. Only the School of Architecture at the National University of Science and Technology briefly lectures on earth construction technology as part of a design module.

All experts agreed that the technological development and innovation of stabilised earth construction technology is not adequate at all in Zimbabwe. Expert "Q" stated, "Cement reduced the individual's, companies, and universities confidence in their own empirical ability to judge technology. In other words, cement becomes the default answer to every single question, and that being the case, even in an institution like the SIRDC (Scientific and Industrial Research and Development Centre) in Zimbabwe. They come back to putting cement into earth structures because they feel that they can't trust themselves in their own abilities. And as I said, it is universal. It takes time for people to regain confidence in their own abilities to judge and assess the situation given the overwhelming strength of this material, cement. You can't build the Twin Towers out of any type of earth construction. But what we always lose sight of is that mass housing in Zimbabwe is not 120 storey's high. It might be two, but normally it is one and therefore, using the material suitable for a 120 storey building to produce a single storey building is something that you have to look at very carefully and critically." The statement explained that the research and technological innovation of contemporary earth construction were carried out by different nongovernmental organisations, such as SIRDC and CSIR. However, these organisations should be confident enough to use their judgement with the help of empirical evidence of research and technological innovation to decide the appropriateness of contemporary earth construction in urban low cost housing. 


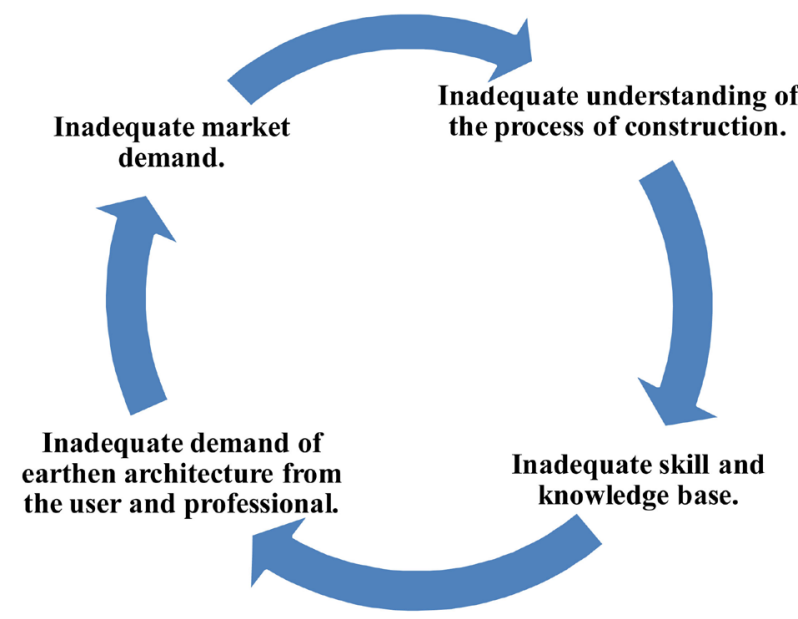

Figure 1. Intra-relationship between inhibitors and drawbacks.

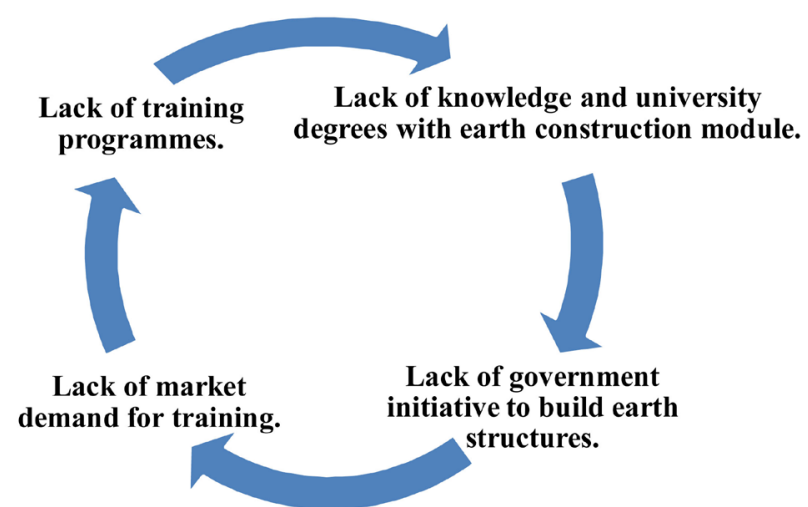

Figure 2. The intra-relationship between inhibitors and drawbacks.

"Conflict of professional's prejudices" negatively influences the adoption of stabilised earth construction, as interviewee "P" stated, "I think if you talk to people in an earth building community, then you will come across people who will tend to fall either in one of two camps, either traditional un-stabilised earth building or stabilised earth buildings. You are going to get very different responses as a result of that. Therefore, in your interview you need to be aware of where the various people you have interviewed are coming from, because they will have their own prejudices. So, you need to have a good idea what their agendas are." It is noted from the statement that, in essence, the professionals who are assigned to promote the stabilised earth construction to address the urban low cost housing crisis in Zimbabwe should be in support of and appreciate the benefits of stabilised earth construction. If not, the adoption of this technology might be influenced negatively. Therefore, there are potential inhibitors and drawbacks which are influencing the adoption of stabilised earth construction to address the urban low cost housing crisis in Zimbabwe. Table 4 summarises the inhibitors validated from the in-depth interviews.

\section{Conclusion}

This paper has investigated the state of the art review of literature and identified inhibitors influencing the adoption of contemporary earth construction in urban housing and refined and validated them through a series of in-depth interviews. It is found that there is a lack of structured research carried out to date to identify the inhibitors. Therefore, it was imperative to empirically substantiate the findings of the literature review and validate them through an appropriate research technique to identify the inhibitors influencing adoption of stabilised earth construction in Zimbabwe. A series of questions was put to the Zimbabwean experts to refine and validate the 
Table 4. Inhibitors influencing adoption of stabilised earth construction in Zimbabwe urban low cost housing.

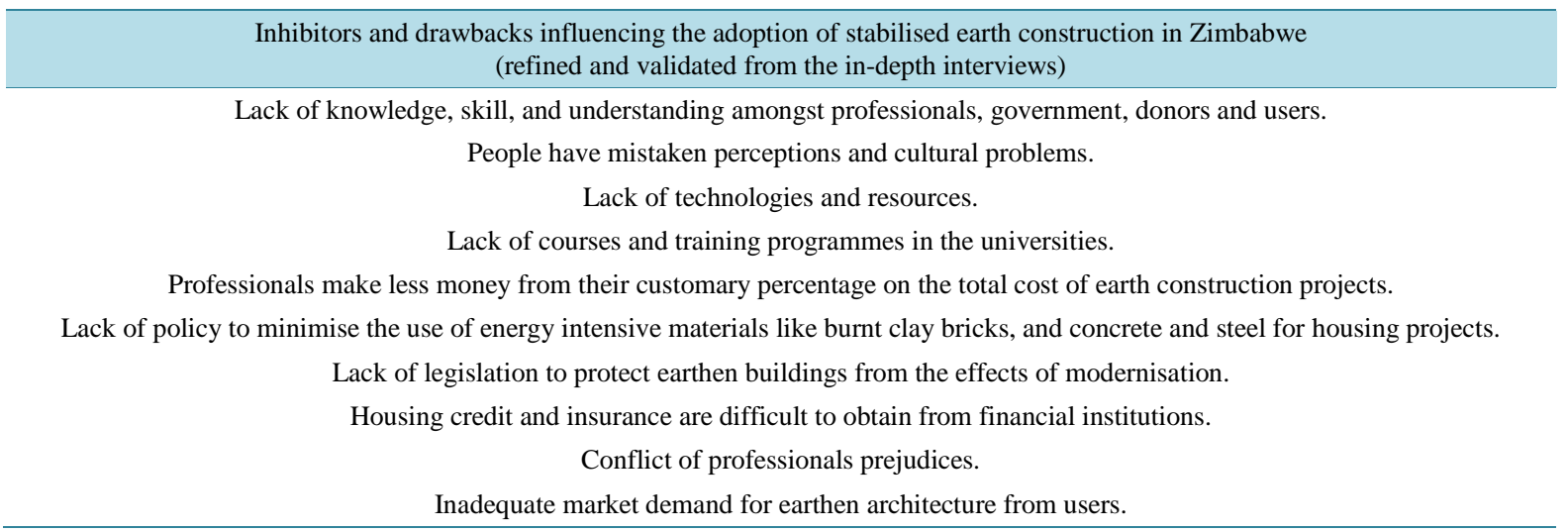

inhibitors found in the literature review. There were ten inhibitors refined and validated as opposed to ten (10) identified in the literature review in which two new inhibitors were found considering the Zimbabwean situation. It is important to note here that two new inhibitors (number 9 and 10 in Table 4) were identified in the in-depth interviews which are negatively influencing the adoption of stabilised earth construction in Zimbabwe. New inhibitor of 9 indicated that the prejudices resulted from the lack of knowledge and exposure of the Zimbabwean construction professionals badly effecting the wide spread adoption of earth construction in Zimbabwe. Furthermore, the majority of experts stated that inhibitors are intra-related and therefore influence each other. For example, inadequate demand of earthen architecture by the Zimbabwean made it less in demand in the market and less demand of this technology in the market encouraged less professionals to be trained in this technology and lack of training resulted in the lack of understanding of this technology.

\section{References}

[1] UN HABITAT (2010) The State of African Cities 2010, Governance, Inequality and Urban Land Markets. UNEP, Nairobi, Kenya.

[2] Srivinas, H. (1999) Sites and Services in Urban Squatters and Slums. http://www.gdrc.org/uem/squatters/s-and-s.html

[3] Kamete, A.Y. (2006) Revisiting the Urban Housing Crisis in Zimbabwe: Some Forgotten Dimensions? Habitat International, 30, 981-995. http://dx.doi.org/10.1016/j.habitatint.2005.08.002

[4] UN HABITAT (1996) Participation in Shelter Strategies at Community Level in Urban Informal Settlements. UN Habitat.

[5] Adam, E.A. and Agib, A.R.A. (2001) Compressed Stabilised Earth Block Manufacture in Sudan. Printed by Graphoprint for the United Nations Educational, Scientific and Cultural Organization, UNESCO, Paris, 11.

[6] Mubaiwa, A. (2002) Earth as an Alternative Building Material for Affordable and Comfortable Housing in Zimbabwe: Undergraduate Dissertation. Department of Architecture, National University of Science and Technology, Bulawayo, Zimbabwe.

[7] Zami, M.S. and Lee, A. (2008) Constraints of Earth Construction Zimbabwe-Some Possible Solutions. The 8th International Postgraduate Research Conference, 26-27 June 2008, the Czech Technical University of Prague (CVUT), Czech Republic.

[8] Reddy, B.V. and Mani, M. (2007) Preface: Proceedings, International Symposium on Earthen Structures, Indian Institute of Science, Bangalore, 22-24 August 2007. Interline Publishing, India.

[9] Baiche, B., Osmani, M., Hadjri, K. and Chifunda, C. (2008) Attitude towards Earth Construction in the Developing World: A Case Study from Zambia. CIB W107 Construction in Developing World Countries International Symposium, “Construction in Developing Countries: Procurement, Ethics and Technology", 16-18 January 2008, Trinidad and Tobago, West Indies.

[10] Olotuah, A.O. (2002) Recourse to Earth for Low-Cost Housing in Nigeria. Building and Environment, 37, $123-129$. http://dx.doi.org/10.1016/S0360-1323(00)00081-0

[11] Longfoot, B.R. (2003) Earth Building in Botswana: Building Blocks Made from Kgalagadi Sand. University of Technology, Sydney, 7 March 2003. http://www.dab.uts.edu.au/ebrf/research/botswana_1.html

[12] Tyrell, D. (1996) Prospects for Sustainable Human Development in Zambia: More Choices for Our People. Govern- 
ment of the Republic of Zambia, Lusaka.

[13] Mususa, P.N. and Wood, B. (2004) The Creating of a Sustainable Building Industry in the Housing Sector of Lusaka, Zambia.

[14] CRATerre (2005) Earth Architecture in Uganda: Pilot Project in Bushennyi 2002-2004. CRATerre-EAG Publications, Grenoble, 34.

[15] Morton, T. (2007) Towards the Development of Contemporary Earth Construction in the UK: Drivers and Benefits of Earth Masonry as a Sustainable Mainstream Construction Technique. International Symposium on Earthen Structures, Bangalore, 22-24 August 2007, 377, 379, 383.

[16] Norton, J. (1997) Building with Earth: A Handbook. 2nd Edition, Intermediate Technology Publications, London, 8.

[17] Chaudhury, S. (2007) Promotion of Earthen Structures in Housing-The Issue of “Acceptability”. International Symposium on Earthen Structures, Bangalore, 22-24 August 2007, 101-106.

[18] Kateregga, J.K. (1983) Improvement and Use of Earth Construction Products for Low Cost Housing. Appropriate Building Materials for Low Cost Housing, African Region. Proceedings of a Symposium, Nairobi, 1983, Vol. 1.

[19] Blondet, M. and Aguilar, R. (2007) Seismic Protection of Earthen Buildings. International Symposium on Earthen Structures, Bangalore, 22-24 August 2007, 8.

[20] Jagadish, K.S. (2007) Earth Construction Today: Prospects and Tasks. International Symposium on Earthen Structures, Bangalore, 22-24 August 2007, 26-27.

[21] Hadjri, K., Osmani, M., Baiche, B. and Chifunda, C. (2007) Attitude towards Earth Building for Zambian Housing Provision. Proceedings of the ICE Institution of Civil Engineers, Engineering Sustainability 160, Issue ES3, 143.

[22] Maini, S. (2005) Earthen Architecture for Sustainable Habitat and Compressed Stabilised Earth Block Technology. Progrmmae of the City on Heritage Lecture on Clay Architecture and Building Techniques by Compressed Earth, High Commission of Ryadh City Development. The Auroville Earth Institute, Auroville Building Centre-INDIA.

[23] Minke, G. (2006) Building with Earth, Design and Technology of a Sustainable Architecture. Birkhauser Publishers for Architecture, Berlin, 18.

[24] Sojkowski, J. (2002) Zambian Vernacular. Online Paper, Architecture Week Website.

[25] Woolley, T. (2004) The Role of Low Impact Building Materials in Sustainable Construction: The Potential for Hemp. Sustainable Building 2004 Africa Conference, Western Cape.

[26] Houben, H., Doat, P., Fontaine, L., Anger, R., Aedo, W.C., Olagnon, C. and Damme, H.V. (2007) Innovative Approaches in Educational Pedagogy for Earthen Architecture. International Symposium on Earthen Structures, Bangalore, 22-24 August 2007, 38-43.

[27] Woolley, T. and Caleyron, N. (2003) Overcoming the Barriers to the Greater Development and Use of Environmentally Friendly Construction Materials. CIB Sustainable Buildings 2003, Oslo.

[28] Cassell, R.O. (1993) A Traditional Research Paper: Rammed Earth Construction, The Compaction of Successive Layers of Earth between Forms to Build a Wall. http://webs.ashlandctc.org/jnapora/hum-faculty/syllabi/trad.html

[29] Dobson, S. (2000) Continuity of Tradition: New Earth Building. Terra 2000, Torquay, England. http://rammedearth.davis.net.au/Terra2000.php

[30] Castells, S.B. and Laperal, E.H. (2007) Spanish Architects Working on Earth. International Symposium on Earthen Structures, Bangalore, 22-24 August 2007, 93-100.

[31] King, B. (1996) Buildings of Earth and Straw: Structural Design for Rammed Earth and Straw-Bale Architecture. Ecological Design Press, California, 5.

[32] Elizabeth, L. (2005) The Natural Building Movement. In: Elizabeth, L. and Adams, C., Eds., Alternative Construction: Contemporary Natural Building Methods, John Wiley \& Sons, Inc., New York.

[33] Adams, C. (2005) The Realities of Specifying Environmental Building Materials. In: Elizabeth, L. and Adams, C., Eds., Alternative Construction: Contemporary Natural Building Methods, John Wiley and Sons, Inc., New York.

[34] Lal, A.K. (1995) Handbook of Low Cost Housing. New Age International Publishers, New Delhi, 124.

[35] Eisenberg, D. (2005) A New Context for Building Codes and Regulation. In: Elizabeth, L. and Adams, C., Eds., Alternative Construction: Contemporary Natural Building Methods, John Wiley \& Sons, Inc., New York.

[36] Robinson, S. (1939) “Houses Dirt Cheap.” The Rotarian August 1939: 24. Department of Agriculture, Washington DC.

[37] Zami, M.S. and Lee, A. (2011) Inhibitors of Adopting Stabilised Earth Construction to Address Urban Low Cost Housing Crisis-An Understanding by Construction Professionals. Journal of Building Appraisal (JBA), 6, 227-240. Palgrave Macmillan Publishers, Houndmills, Basingstoke, Hampshire, RG21 6XS. http://www.palgrave-journals.com/jba/journal/v6/n3/full/jba201025a.html

[38] Kelly, G. (1970) A Brief Introduction to Personal Construct Theory. In: Bannister, D., Ed., Perspectives in Personal 
Construct Theory, Academic Press, London, 1-29.

[39] Pidd, M. (1996) Tools for Thinking: Modelling in Management Science. John Wiley, Chichester, 153.

[40] Loosemore, M. (1999) International Construction Management Research: Cultural Sensitivity in Methodological Design. Construction Management and Economics, 17, 553-561. http://dx.doi.org/10.1080/014461999371178

[41] Chan, P.W. (2004) An Interpretivistic Approach to Understand the Factors that Affect Construction Labour Productivity. PhD Thesis, Heriot-Watt University, Edinburgh.

[42] Wallace Foundation Website (2009) Market Research Workbooks and Appendices. Workbook E: In Depth Interview. http://www.wallacefoundation.org/KnowledgeCenter/KnowledgeTopics/CurrentAreasofFocus/Out-Of-SchoolLearning /Pages/msr.aspx

[43] Boyce, C. and Neale, P. (2006) Conducting In-Depth Interview: A Guide for Designing and Conducting In-Depth Interviews for Evaluation Input. Pathfinder International Tool Series, Monitoring and Evaluation-2. http://www.pathfind.org/site/DocServer/m_e_tool_series_indepth_interviews.pdf?docID=6301

[44] MLGPWNH (Ministry of Local Government, Public Works and National Housing) (2004) New National Housing Standards for High, Medium and Low Density Residential Areas. Circular Number 70, Section 3.1.5, Harare. 